\title{
ADVERTISING RESEARCHES AND SALES GROWTH - SOME MODELS FOR PREDICTING ADVERTISING INFLUENCE IN DIFFERENT COMPANIES
}

\author{
L. Spasova* \\ Department of Social Sciences and Business Language Training, Trakia University, \\ Stara Zagora, Bulgaria
}

\begin{abstract}
The advertising researches are a very important specialized form of the contemporary marketing researches, conducted to improve the efficiency of the contemporary advertising. More and more companies report conduct customers' researches in an attempt to develop the advertising business, to improve relationships with the different targeted groups, to determine consumers' perceptions of relevant advertising and go on.

The aim of this research report is to demonstrate through real world examples of businesses that the different varieties advertising researches can significantly influence on the users' thinking and behavior. The following tasks are solved in order to achieve this goal:

$>$ Presentation of the leading organizations that fail to have an impact on different target groups through advertising and occupy a large market share.

$>$ Survey of the main strategies and techniques from business organizations to realize the different types of advertisings.

The methods used for achieving this goal and resolving the tasks are: systemic and structural approach, analysis of advertising media and advertisings, analysis of successful practices, comprehensive approach.
\end{abstract}

Key words: target groups, comprehensive approach, types of advertisings, sales growth.

\section{INTRODUCTION}

The advertising researches are a very important specialized form of the contemporary marketing researches, conducted to improve the efficiency of the contemporary advertising. More and more companies report conduct customers' researches in an attempt to develop the advertising business, to improve relationships with the different targeted groups, to determine consumers' perceptions of relevant advertising and go on.

\section{BASIC ADVERTISING RESEARCHES AS A PART OF THE DEVELOPMENT OF ADVERTISING}

Advertising as any other science, has its history and development. Here can be seen

\footnotetext{
*Correspondence to: Lyubomira Venkova Spasova, Department of Social Sciences and Business Language Training, Faculty of Economics, Trakia University, Stara Zagora, Bulgaria,e-mail: liubomira1975@abv.bg.
}

some leading dates, showing the contribution of various researchers for carrying out advertising researches. The real beginning was in 1895 when NW AER conducts custom research in an attempt to win the advertising business of Nichols-Shepard - this is a manufacturer of agricultural machinery. Later the company Harolow Gale from the University of Minnesota develops the questionnaires to gather opinions about different advertisings from the public. At the same time advertising became the subject of serious scientific researches and big popularity has the books of Walter Dill Scott, which sets the principles of modern psychology. (10-11) The author also displays the six basic principles of advertising as timeliness, visibility, reproducibility, uniformity, reliability and associability. George B. Waldron conducts qualitative researches for Mahin's Advertising Agency. This is the time when marketing surveys are becoming an industry. In 1911 Kellogg, famous advertising manager, creates the Association of National 
Advertisers which is now known as the Association of National Advertising managers. He is trying to determine the number of readers on which the influence of print advertising. In 1916 R.O. Eastman starts his own company, Eastman Research Bureau which serves customers as Cosmopolitan, Christian Herald and General Electric.

\section{ADVERTISING AND SALES - CLOSELY RELATED CONCEPTS}

In times of computer technology which allowing advertisers to perform various manipulations, it is clear that advertising research can not predict sales. The persuasion, also known as motivation, can direct users to specific products and services, but not to determine the decision to purchase. This depends on other factors such as purchasing power, region, family environment, habits and other factors. In this line of thoughts any advertising study is completely contingent nature and elements such as attract attention, awakening of interest, creating a desire for possession become even more difficult to measure.

In the field of marketing advertising may be used for the construction of a fixed image of a product (advertisements for Coca Cola) or cause a quick sale (such as advertisings from Sears for Saturday sales. Advertising can lead effectively in geographically dispersed buyers. Some forms of advertising (television advertising) usually require a large budget and it is not clear whether they would generate sufficient sales of the company. (5) There are also such as newspaper advertisings that are distributed with a small budget, but research shows that consumers are treated with greater confidence in them.

\section{CONSUMER PROMOTIONS LEAD TO SALES PROMOTIONS}

Although the tools of promotional sales coupons, contests, awards and more- are very different, they offer three major advantages. Firstly, it is communication that attracts attention and usually carries information, which may take the user to the product. Second is the stimulus that includes a discount or promotion that has value for the buyer. Thirdly is the invitation that includes clear call customers to engage in the transaction immediately. Promotional sales can be used for short-term goals, as enhancing the product offer and increase sales. In recent years the proportion of advertising and promotional sales is about 60:40. Now in many companies producing consumer packaged goods (food) promotional sales accounted 65:75 per cent of the total promotional budget. This trend, especially in the consumer market, several factors contribute. Some of the factors are as follows: promotion as effective sales tool, reminder advertising, especially in the mature products. For example, advertisements for Coca Cola aim to remind consumers to buy. Such is the role of kinship generic advertising - reinforcing that seeks to assure current customers that have made the right choice. As for the car advertisings, there often appear satisfied customers who enjoy the special qualities of his new car. (3)

Consequently, any advertising must be based on an analysis of the current market situation. If the product class is mature stage, the company is a market leader and the use of the brand is low, but the brand is superior to that of the leader the right goal is to convince the market of the superiority of the brand.

\section{PSYCHOLOGICAL APPROACHES TO PREDICT THE IMPACT OF ADVERTISING}

The main question that we put is: What makes us to buy some products and not others? And why do we prefer some brands or companies over others? Some experts give some answers but they are not enough. And the other basic question is: Can different types of advertisements influence our behavior?

In an effort to answer these questions and to understand consumer behavior, advertisers make a lot of advertising researches. Also the different experts with diverse research strategies as psychological, social and cultural can help advertisers understand costumers and assess the effectiveness of advertising messages directed to them. The specific research conducts in this preliminary phase may include interviews with costumers to find out what they like or do not like about the specific brand. This is very important information for a company because the particular kinds of research conduct in an advertising campaign are always tailored to serve the needs of those who produce the advertisings as well as the interests of the clients whose products are promoted. (12)

Advertising contents analysis at why effective advertisements work or why not. This is done by dissecting the emotional appeal of advertisements, by the effective idea and first of all by the methods advertisements use to appeal to the subrational side of the target audience. While people are confronted by hundreds of advertisements each day, only a few of these attract the attention of their 
intended audiences. Expert Jib Fowles says that the small number of advertisements that do succeed do so through "something primary and primitive, an emotional appeal, that in effect is the thin edge of the wedge, trying to find its way into a mind" (2)

Fowles drew on earlier researches by psychologist Henry A. Murray to describe 15 emotional appeals used by advertisers to wedge messages deep into the human mind. According to Fowles, advertisers try to circumvent the skeptical, careful, logical side of the consumers. Instead, the marker aims for the side of the consumer that has unfulfilled desires. This is very interesting information because consumer should be mindful of this approach and can protect against responding to such emotional advertising appeals.

Even more interesting is the point of view of Marshal McLuhan who wrote about the way advertisements "worm" their way into the psyche. The late philosopher wrote about this phenomenon in media. According to the author "the continuous pressure is to create advertisings more and more in the image of audience motives and desires." (14)

The appeals are the last verbal part of the advertisement. They are one of the most important elements, since along with the title, appeal read in most cases in print advertising. Their functions are two - to repeat the main points of the text and to give a finished look. A good example of how this works is expressed by what happens when we see, or fleeting seconds, a photo of a lone rancher at his work. The word Marlboro comes to mind with swift immediacy. The advertising has succeeded. It has reached into the psyche to find a subject of emotional appeal to use as a wedge to drive the product name home. If the presentation of the ranch we think of Marlboro, or if the naming of a purple cow, the user connects with Milka, therefore clip has worked.

According Fowles advertising appeals, carrying some emotions, divided into 15 appeals. These include lower the need for sex, security, care, fame, attention, autonomy, sense of safety, aesthetic senses and go on.

If most of us take the first emotional appeal, the need for sex, the most prevalent ingredient in advertising, I will focus on sexual drive. Analysis of advertising content made by Mass media in the "Social Survey" shows that only $2 \%$ of all the advertisements take care of sexual desires. Therefore, it is leading the adverts and the impact which turns through it, is very weak. It was found that advertisers are intimidated by the power of sex and create sexual needs, since the advertisement is paid little attention to the product or service. Another reason that may indicate the use of advertisements tied to sex, that will be a different disconnect with the target audience. Sex can be used in influencing the male sex, but this ignores the female part of the audience, i. e. The segmentation is performed on other principles.

There are many other needs that can be met. For example, such is the need for security and family warmth. One such creative that predisposes the user to peace is advertising tied to the purchase of perfume that exudes a sense of intimacy. Also people like to think they are autonomous and independent, but most people, deep down, prefer to have a partner. Nobody likes to be alone. Therefore there are other types of affiliation besides romantic coupled. In advertising mobile operators, for example, show two friends chatting, guys sitting at a bar, families, college parties, all appeal to the need for affiliation.

Of course, there are other needs that might be caused. All basic emotional needs can be created by using different advertising strategies and techniques. Professional advertisers exploit these primitive human needs and thus trigger different engines in the human psyche.

\section{ANALYSIS OF CONSUMER BEHAVIOR - MAIN RELATIONSHIPS WITH SALES GROWTH}

Consumer behavior is the study of the way individuals, groups' people or organizations make decisions with respect to the purchase, consumption and disposal of goods and services. It studies characteristics of individual consumers such as demographics and behavioral variables in an attempt to understand people's wants. The studies of consumer behavior also try to assess influences on the consumer from different groups such as family, friends and society in general.

The consumer behavior study is very important part of a marketing strategy evolved in the late 1950s when companies start realizing they can sell more if they produce goods only after determining that the consumers will buy. This is a very important marketing concept and the experts call it consumer-oriented marketing. The main idea in the marketing concept is that a company 
can be successful if determines the real needs and wants of a targeted market and satisfies this demand better than the competition.

There are many factors that can stimulate the individual user in marketing to buy some or other products. Among the most important reasons are the ways in which the offered products meet consumers' needs, values or goals. Marketing experts also try to understand the reasons why consumers do not want to buy or use a specific product or service. Consumer behavior study also focuses on the ways people acquire and use things as well as the time and place that clients select. Among other things marketers should comply with the basic division of users, namely customers and corporate clients. This clarification is important because individual customers use products and services for final consumption, as well as the needs of the household. Personal costumers are also called end-user or ultimate consumers. Corporate clients, which include various companies, non-profit organizations, institutions and other (for example schools, hospitals, universities) have to buy a large number of products, equipment, and to use the services of other organizations to function fully.

Every consumer also make their choices after deciding how much of the product or service they need, also how often they need it and how much time will be necessary to buy, use and dispose of it. Other key factors are the emotions. According to consumer behavior study, the factors that affect decisions for purchase, usage and disposal of goods and services can be classified into four main groups: the psychological core (the source of knowledge and information), the process of making a decision, lifestyle and household influences also affect the selection of goods and services. People's desire to belong to a certain group and their sense of self determine the external signs they use to express identity.

First of all the experts determine four main applications of the consumer behavior study, but the best known is the preparation and improvement of marketing strategies of companies worldwide. The public policy is the second application, which is very important for the marketers. The third is social marketing that involves getting ideas across to consumers rather than selling something. As a final benefit, studying consumer behavior is expected to help the consumers themselves to make better decisions.
Some experts like B. William have noticed the move towards a global consumer culture, which people are united by their common devotion to certain brands as Coca Cola. (2) The development of technologies has helped cultures worldwide to start mixing, resulting in a significant effect on the globalization of consumer culture. With the growth of the internet, consumers now have easy access to the opinions of other users, which they often trust more than advertisements, and so sales start to grow.

But what do the consumer buy and why? What do the potential clients want? What makes us buy some products and not other? Why do we prefer some brands over other? In an effort to answer these questions, we try to research the different kinds of markets. The market researches can be done through a survey, focus groups, personal interviews, projective techniques, observations, online researches and scanner data. The first-surveys are used when the market researchers want to get specific information, while focus groups are useful when the marketer wants to launch a new product or modify an existing on. The second-personal interviews help researchers to get in-depth information and save a lot of data. Projective techniques are used when a consumer may fell embarrassed to admit to certain opinions, feelings or preferences. The third - observations of consumers help to understand how they make decisions before to buy something. There is an online research that is becoming more popular as most people have computers and access to the Internet. And last but not least is the scanner data method that shows the exact behavior of specific consumers.

\section{ADVERTISEMENT AND ADVERTISEMENT RESEARCHES - SOME MAIN ACHIEVEMENTS IN PRACTICE}

Whenever you analyze users' behavior marketers and advertises look for the dependencies between consumers' behavior and advertisings, to assess what is the next impact on consumer attitudes and desires. This requires the application of different types of advertising researches. Advertising tests are quantitative and qualitative part used to make important management decisions.

General advertising tests divided into three main types: pre-tests, tracking studies and after-tests. Pre-tests are quantitative tests that employ strict measures for quality of advertising, whose values were also measured and compared experimental established 
standard of quantities. So the experts should decide and what improvements can be made, and whether advertising can be put into circulation. Pre-tests are intended "to make better the achievements of advertising by providing diagnostic information of the advertising agency" (7) to improve advertising and customer information to decide whether to start an advertising campaign. Therefore the pre-tests have a dabble role: on the one hand, to provide information to improve advertising; on the other, to provide information on whether or not to launch an advertising campaign.

According to McDonald's with these tests can be "predicted" what would work in the real market and to "understand" what is the reaction of consumers.

There are two principal approaches to the estimate pre-tests: recognition/recall (Recognition/recall) and persuasion/changing attitudes (Persuasion/attitude shift). Tests persuasiveness of advertising (Advertising persuasiveness tests) was introduced for the first time in Schwerin in the 40s of last century. They interrupt the tradition of performance metrics to be viewed through the prism of visibility and remembering her. For effective advertising starts to believe advertising that changed attitudes towards the brand (in approved known brand) or has produced favorable attitudes (in brand new). Attitudes in turn are considered closely related to subsequent purchasing behavior. (6) In the long run these tests are more important and this is expressed in the words of David
Ogilvy: "Never cease to test and your advertisement will never stop trying to improve."

Attitude to pre-tests changed over the years, because the dominant model of persuasion and change of attitudes is subjected to sharp criticism. The user begins to be perceived not as a passive recipient of advertising, but as having a proactive attitude towards it. It has selective choice: to decide what to pay attention. The impact of advertising as part of the change in consumer behavior is measured by tracking tests (Tracking studies).This continuous research, which include the measurement of many different variables behavior, knowledge, thinking, perception, consumer attitudes and are based on different composition samples. (15) In the UK, these studies have the greatest application and to be recognized for a study tracking, it should be the duration of 12 months, and its results report four times for the period.

Director of Strategic Planning of Millward Brown N. Hollis traces the evolution of advertising tracking research in three areas: (3)

- The reasons that cause them;

- What do they want to know;

- What methodology used.

Through interviews in respondents' homes researcher managed to accumulate knowledge about the views of consumers on the rapid development of brands. Hollins indicate three periods, which are presented in Table 1.

Table 1. Evolution of advertising tracking studies

\begin{tabular}{|l|l|l|l|}
\hline Indicators & $50 \mathrm{~s}-60 \mathrm{~s}$ & $70 \mathrm{~s}-90 \mathrm{~s}$ & 2000 \\
\hline What causes them & Development of brands & Fight for market share & $\begin{array}{l}\text { Fragmentation of the } \\
\text { media }\end{array}$ \\
\hline $\begin{array}{l}\text { What do they } \\
\text { want to know }\end{array}$ & Branding & $\begin{array}{l}\text { Creative power of } \\
\text { advertisement }\end{array}$ & $\begin{array}{l}\text { Effectiveness of the } \\
\text { media }\end{array}$ \\
\hline $\begin{array}{l}\text { What } \\
\text { methodology used }\end{array}$ & Interviews in homes & Telephone interviews & Online researches \\
\hline
\end{tabular}

Consumer behavior and the influence of advertising on individual behavioral stages are two maxims, among which researchers seek continuous connection. We should not forget that the consumer is not only an economic partner, but he or she is a person and as such is characterized by the presence or absence of initiative whether alone buys goods used or another he or she buys them.
For example, consumers buy new mobile devices, not because they need them, but because it satisfied their need for prestige and recognition from others for good physical condition. Undoubtedly very important are the scale of consumption and consumer motivation as well as consumer opinion for the commodity. Some of the characteristics are strongly influenced by economic factors, 
and others like consumer behavior are closely related to the quality of the user as a person.

The process of decision making and its features, as well as all mental processes that accompany it are subject to an enhanced scientific interest. (8) Follow the ability of advertising to affect it in the direction of acceleration of the purchasing decision. $\mathrm{H}$. Yunk explores the process of making a purchase decision, seeking connection with the advertising response. Stages of making a purchase decision and the factors affecting each stage are presented in the following table.

Table 2. Stages of making a purchase decision

\begin{tabular}{|c|c|c|c|c|}
\hline $\begin{array}{l}\text { Stages of } \\
\text { making a } \\
\text { purchase } \\
\text { decision }\end{array}$ & $\begin{array}{l}\text { Use of } \\
\text { advertisement }\end{array}$ & Objectives of advertisement & $\begin{array}{l}\text { External factors } \\
\text { of influence }\end{array}$ & $\begin{array}{l}\text { Other } \\
\text { factors of } \\
\text { influence }\end{array}$ \\
\hline $\begin{array}{l}\text { Awareness } \\
\text { needs }\end{array}$ & $\begin{array}{l}\text { Introductory } \\
\text { advertising }\end{array}$ & $\begin{array}{ll} & \text { Awareness } \\
- & \text { Understanding }\end{array}$ & $\begin{array}{l}\text { All steps of the } \\
\text { forgetfulness }\end{array}$ & \begin{tabular}{|l|}
$\begin{array}{l}\text { Social } \\
\text { environment }\end{array}$ \\
\end{tabular} \\
\hline $\begin{array}{l}\text { Preparation for } \\
\text { purchase }\end{array}$ & $\begin{array}{l}\text { Introductory } \\
\text { advertising }\end{array}$ & $\begin{array}{ll}\text { - } & \text { Formation of attitude } \\
\text { - } & \text { Formation of motivation }\end{array}$ & \begin{tabular}{|l|}
$\begin{array}{l}\text { Negative impact } \\
\text { of competitive } \\
\text { advertising }\end{array}$ \\
\end{tabular} & $\begin{array}{l}\text { Family and } \\
\text { friends }\end{array}$ \\
\hline $\begin{array}{l}\text { Purchase } \\
\text { decision }\end{array}$ & $\begin{array}{l}\text { Reminder } \\
\text { advertising }\end{array}$ & Action & $\begin{array}{l}\text { Intensive } \\
\text { advertising }\end{array}$ & Culture \\
\hline Use & $\begin{array}{l}\text { Supporting } \\
\text { advertising }\end{array}$ & Detection of latent benefits & \begin{tabular}{|l|} 
Intensive \\
advertising
\end{tabular} & Religion \\
\hline $\begin{array}{l}\text { Behavior after } \\
\text { use }\end{array}$ & $\begin{array}{l}\text { Supporting } \\
\text { advertising }\end{array}$ & $\begin{array}{l}\text { Reinforcing a feeling impact on } \\
\text { repeat purchases }\end{array}$ & $\begin{array}{l}\text { Passive } \\
\text { advertising }\end{array}$ & $\begin{array}{l}\text { Individual } \\
\text { qualities }\end{array}$ \\
\hline
\end{tabular}

\section{CONCLUSIONS}

In a study of consumer behavior and seek its relationships with the general behavioral tendencies, such behavior is directed against other people or there is a desire to include. As a result, demand for the relationship between the activity-related trends and consumer behavior offers many classifications based on different signs: a tendency to adopt innovation, openness to outside influence contractibility and interest in the world around them and so on.

The paper aimed to discuss the influence of the advertisings for the customer behavior and for the sales growth because the advertising has the power to persuade, to change markets and change consumer behavior based on psychological researches. The companies that master the creative guidance and the testing systems to research the costumer behavior and develop great advertisings can own the future. Advertising research is only conducted when there is a perceived need for it and when its cost is deemed necessary to the success of the campaign. Even then, the research is never systematic. Rather, it is always applied and directed toward answering specific questions relevant to the project at hand.

\section{REFERENCES}

1. Doganov, D., Duranchev, B., Katrandziev, H., Integrated Marketing Communications. UNSS, Sofia, p. 56-62, 2003.
2. Fowles, J., International journal of advertising and marketing, 1999.

3. Health, R., Can tracking studies tell lies? International journal of advertising, vol.18, No.2, 1999

4. Hopkins, K. Scientific Advertising, Princeps, Varna, 1994.

5. Jon Steel, Truth, Lies, and Advertising: The Art of Account Planning, New York: John Wiley \& Sons, Inc., 1998.

6. Jones, J.P., Latest advertising research developments from the USA, London, 1996.

7. Jones, J., P., Getting it right the first time, Admap Monograph, 1996.

8. Junk, H., Consumer behavior and economic growth in the modern economy, London, 1982.

9. Ogilvy.D. Confessions of advertising, p.43-44, 1963.

10.Scott, W.D.The theory of advertising, Boston, p.765-766, 1903;

11.Scott, W.D., The psychology of advertising, B., p.120-122, 1908.

12.William M., Sex and advertising, 2007

13.William M., Media and advertising, 2009.

14. Young, C., Page, A. ; A model for predicting advertising quality as a key to driving sales growth, Vol. 54, No. 4, 2014, p.393-397.

15.Zhelev, S., Advertising researches, UNSS, p. 226-268, 2013 
